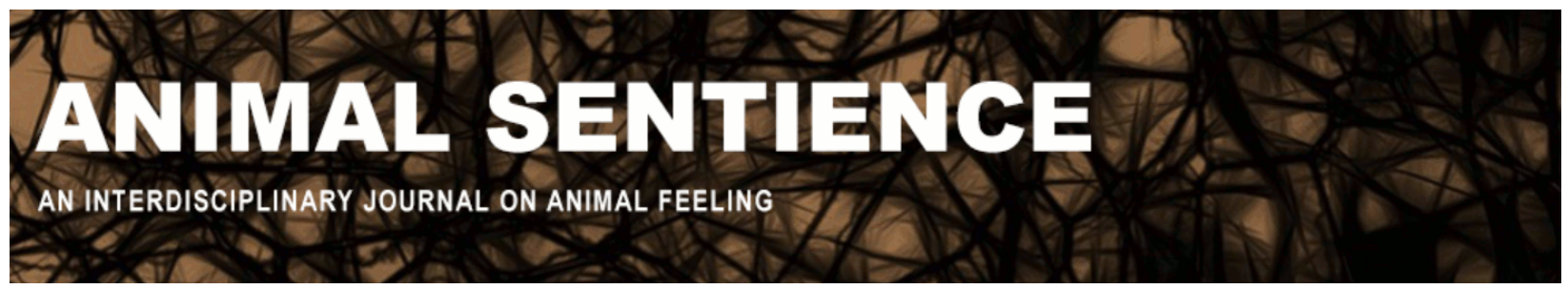

Chapman, Colin A. and Huffman, Michael A. (2018) Why do we want to think humans are different?. Animal Sentience 23(1)

DOI: $10.51291 / 2377-7478.1358$

Date of submission: 2018-07-06

Date of acceptance: 2018-12-17

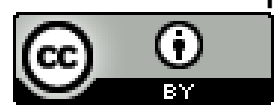

This article has appeared in the journal Animal

Sentience, a peer-reviewed journal on animal

cognition and feeling. It has been made open access,

free for all, by WellBeing International and deposited

in the WBI Studies Repository. For more information,

please contact

wbisr-info@wellbeingintl.org.

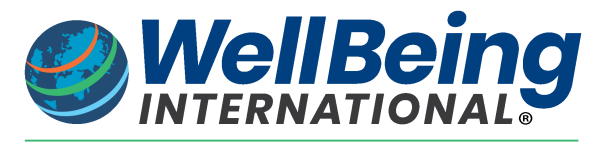

SOLUTIONS FOR PEOPLE, ANIMALS AND ENVIRONMENT 
Call for Commentary: Animal Sentience publishes Open Peer Commentary on all accepted target articles. Target articles are peer-reviewed. Commentaries are editorially reviewed. There are submitted commentaries as well as invited commentaries. Commentaries appear as soon as they have been reviewed, revised and accepted. Target article authors may respond to their commentaries individually or in a joint response to multiple commentaries.

Instructions: animalstudiesrepository.org/animsent/guidelines.html

\title{
Why do we want to think humans are different?
}

\author{
Colin A. Chapman \\ Department of Anthropology, McGill University, Montreal, Canada \\ Shaanxi Key Laboratory for Animal Conservation, Northwest University, Xi'an, China \\ School of Life Sciences, University of KwaZulu-Natal, Pietermaritzburg, South Africa
}

\section{Michael A. Huffman \\ Section of Social Systems Evolution, Primate Research Institute, Kyoto University, Japan}

\begin{abstract}
One harmful consequence of creating categories where one group is unique and superior to others is that it justifies committing negative, often atrocious, acts on the members of the inferior group. Correcting divisive human categorizations (racial superiority, gender superiority) has bettered society. Scholars have often claimed that humans are unique and superior to nonhuman animals. These claims need to be reevaluated. Many have already been refuted. Animals have been shown to outperform humans in many tasks, including cognitive ones. Here we raise the question: Has the false sense of superiority been used to justify human cruelty to animals?
\end{abstract}

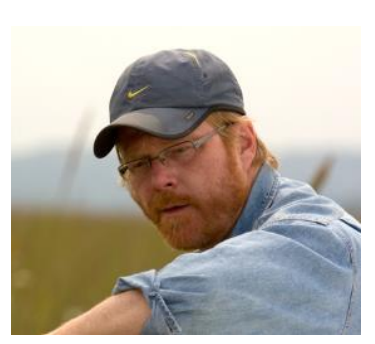

Colin A. Chapman has conducted research in Kibale National Park in Uganda for 30 years, contributed to the park's development and protection, and devoted great effort to promoting conservation by helping rural communities. His research focuses on how the environment influences animal abundance and social organization. Given animals' plight, he has applied his research to conservation. Fellow of the Royal Society of Canada, Killam Fellow and Conservation Fellow to the Wildlife Conservation Society, Chapman was advisor to National Geographic and received the Velan Award for Humanitarian Service. Website

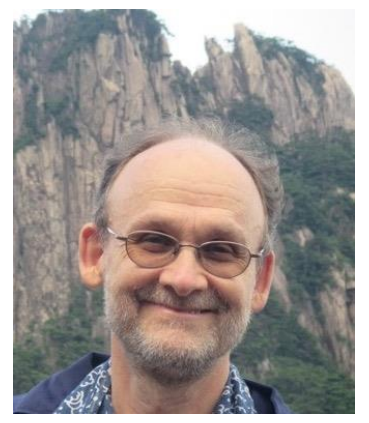

Michael A. Huffman, Primate Research Institute of Kyoto University, publishes extensively in the fields of cultural primatology, animal self-medication, ethnobotany, pharmacology, primate host-parasite ecology, reproductive behavior and physiology, behavioral endocrinology, phylogeography, and historical primatology. He has published on over 15 primates and other mammals in Japan, Taiwan, Sri Lanka, India, Vietnam, China, Bangladesh, Tanzania, Uganda, Guinea, South Africa, and Brazil. He is deeply committed to building bridges through international collaborations and mentoring in over 35 countries. Website 
Humans have the propensity to place things into categories (i.e., good vs. bad, full vs. empty, black vs. white), which can directly shape how we view the world. Since categorization shapes our actions, it is important to evaluate their validity and distinctness and the degree to which one category blurs into the next. One categorization that has intrigued scholars for centuries is that of humans versus nonhuman animals. We often put humans on a pedestal, as unique and superior to all other animals: one of a kind; unlike any other animal. For example, in the $17^{\text {th }}$ century, Rene Descartes stated that only people were creatures of reason, linked to the mind of God, while animals were merely machines made of flesh. His follower Nicolas Malebranche went on to say that animals "eat without pleasure, cry without pain, grow without knowing it: they desire nothing, fear nothing, know nothing." Today Descartes's and Malebranche's statements may seem extreme and wrong (Call, 2006), but they clearly reflect the propensity to see animals and humans as very different and humans as superior.

The view of humans and animals has changed since the $17^{\text {th }}$ century (Fuentes, 2018; Marks, 2016; Van Schaik, 2016), thus these categories need to be reevaluated. Other categorizations have changed dramatically over time, with very positive effects on human societies. When the U.S. Declaration of Independence and Constitution was written, "only white male property holders [were] deemed adequately endowed to be included in the category of personhood" (US 1776). This is no longer the definition of personhood. In fact, the question of whether great apes warrant being accorded personhood is generating much academic interest today (Kurki and Pietrzykowski, 2017; Shyam, 2015; Wise, 2014).

A second reason to reevaluate the human/animal distinction is that many of our previous criteria for human uniqueness have proved wrong. Thomas Carlyle (1833) stated that "Man is a tool-using animal. Without tools he is nothing, with tools he is all" (Carlyle, 1833). This definition of "Man the Tool Maker" was largely viewed as true until the 1960s, when Jane Goodall's observations of chimpanzees (Pan troglodytes) using tools to extract termites from their mounds (with the help of publicity from National Geographic) eventually invalidated Carlyle's definition. It had taken well over a century (Goodall, 1986; Goodall, 1964). Prior to the Goodall findings, there had already been considerable evidence, largely ignored, that the definition was flawed. For example, in 1925 Köhler reported a series of simple experiments that clearly demonstrated chimpanzees could use tools and even cooperate in tool use to obtain food rewards. The chimpanzees would pile boxes one on top of another and then use sticks (even putting two sticks together) to reach a food reward hung high above their heads. Several primate species have now been shown to be habitual tool users, some maintaining tool-using cultures for hundreds of generations (Haslam et al., 2017).

Today we know that tools are also used by many non-primate species such as elephants (Hart and Hart, 1994), Caledonia crows (van Casteren, 2017), African grey parrots (Pepperberg, 2004), sea otters (Hall and Schaller, 1964; Fujii et al., 2014), rodents (Nagano and Aoyama, 2017), octopuses (Finn et al., 2009), and some fish (Bernardi, 2012).

A similar failed criterion had been put forward in 1891 by Sir William Osler, who stated: "A desire to take medicine is, perhaps, the great feature which distinguishes man from other animals." The subsequent extensive documentation of medicinal plant use by chimpanzees (Figure 1) and other primates opened the flood gates for research in this area (Huffman, 1997; Huffman, 2007), leading to examples of medicine use not only by other mammals (e.g., elephants, bears, civets, coatis, porcupines), but also birds (e.g., snow 
geese, finches, raptors) and insects (e.g., bumble bees, ants, butterflies) (Engel, 2002; Huffman, 2007).

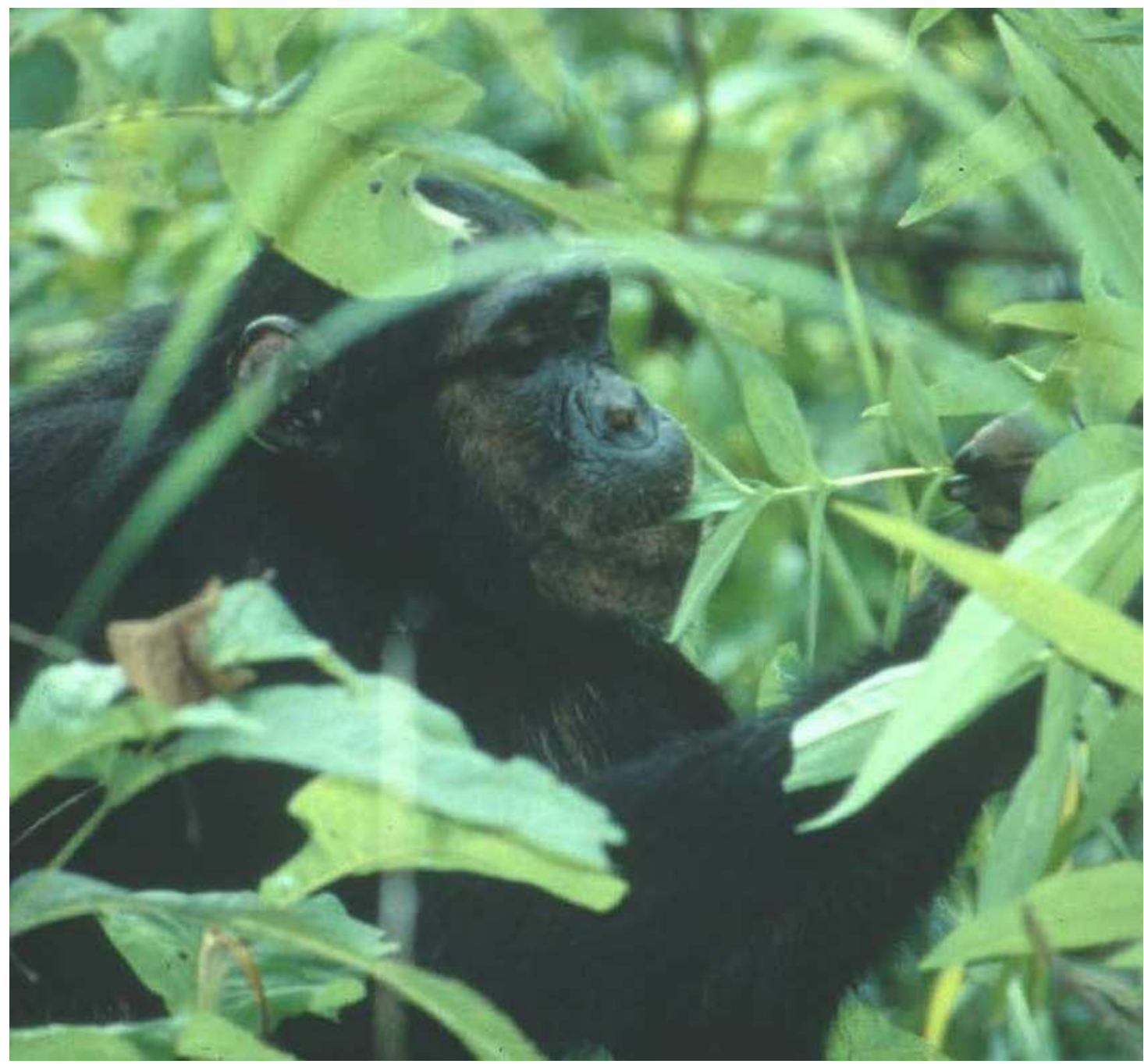

Figure 1: Chimpanzees use plants for their curative properties. Here the individual is folding and swallowing the whole leaves of Aspilia mossambicensis, one of over 40 different species ingested in a way that has been shown to physically purge intestinal worms from Africa great apes (Huffman et al., 1997).

Chu (2014) suggested that humans are unique in their ability to build complex structures. A number of authors have since echoed this (Fuentes, 2017; Marks, 2015) despite the evidence of complex living constructions by animals such as beavers (Castor canadensis), birds, bees and wasps (Doucet et al., 1994; Hansell, 2000; Hepburn et al., 2016). Termite mounds are remarkable structures with specific areas built for different purposes, elaborate features for draining water and cooling the mound, and even gardens to cultivate fungi as a source of food and medicine (Darlington, 1985; Korb, 2003; Korb, 2010).

These and many other such claims about putative defining differences between humans and animals span from 1833 to 2014 have proved wrong. Yet the desire to see humans as unique still remains. Is this a valid scientific question? One of the distinctive 
features of science is hypothesis testing (Cartmill, 1990; Popper, 1968). If hypotheses about human uniqueness repeatedly prove to be wrong for one trait after another, does this not imply that the hypothesis itself is wrong? We can keep resurrecting the hypothesis with new traits not yet considered, but to what end?

Evolutionary theory is a widely accepted explanation for the diversity of life on the planet. If uniqueness were intended to mean humans are one of a kind, unlike anything else, this would contradict evolution. Evolution consists of changes in genetically coded traits: if a new trait is advantageous for survival and reproduction in the environmental setting in which it occurs, its frequency will increase. Any trait (e.g., human intelligence) must have its roots in common ancestors; there are no "Hopeful Monsters" as proposed by Goldschmidt (1940). Matt Cartmill (1990) summarized this well when reviewing some of the early critics of natural selection. Some scholars argued that natural selection could not account for some human traits, such as our intellectual capacities and our moral faculties, as they could not have been generated through survival of the fittest variants among apelike ancestors. This argument was countered by Darwin (1871) and his followers who simply asserted that these traits had selective advantages and thus the moral and intellectual gap between humans and other higher mammals was only a matter of degree. All genetic traits are derived from predecessor traits; thus, there are similarities among the closest living relatives.

Many claims about the uniqueness of people state or imply that humans are superior to animals. In both Judaism and Christianity, humans are said to be made in the image of god and given dominion over lower creatures (Genesis). Aristotle believed that plants and animals were made for the sake of humans (Taylor, 1984). A number of religions in the Orient believe in the concept of a gradation of beings, with humans being the ultimate state. In Jainism there are four states with gods the highest, humans second, suffering in hell the third, and plants and animals last (Laidlaw, 1995). Belief in human superiority is clearly deep-rooted. When scholars make such assertions today, they often select traits on an ad hoc basis according to what they view as important among the things at which humans excel. Examples include the traits discussed above (tool use, medicine, construction). As part of Tetsuro Matsuzawa's 40 years of research on chimpanzee cognition (Matsuzawa, 2017), one candidate, the ability to solve complex problems, was examined in a beautiful study by Inoue and Matsuzawa (2007). They developed a memory test in which numbers where shown on a computer screen and then covered by opaque boxes. Chimpanzees were rewarded if they touched the boxes in the sequence that the numbers had been represented (i.e., 1 to 5). The researchers concluded that their study "shows that young chimpanzees can quickly grasp many numerals at a glance, with no decline in performance as the hold duration is varied. Moreover, the young ones showed better performance than adults in the memory task. Our study shows that young chimpanzees have an extraordinary working memory capability for numerical recollection, even better than that of human adults" (Inoue and Matsuzawa, 2007).

Claims of human superiority are used to justify human cruelty toward animals (Arluke, 2017), such as those raised for food (Taylor and Fraser, 2017). They mirror how claims of ethnic superiority are used to justify atrocities and even genocide against people trying to escape from famine or violence (Kunst et al., 2017; Staub, 1989).

We think it is time for our species to use our intellect to change our actions. This must start by recognizing that while differences exist between animals and humans or 
among cultures or peoples, they should not be ranked vertically. Differences are value-free and of interest because they provide diversity, whether genetic or cultural; studying them allows us to better understand ourselves. Problems arise only when a cultural belief infringes on the rights and safety of others (Mechoulan, 2017; Twining et al., 2000; Bauman et al., 2014).

There are many differences (and similarities) between human and nonhuman species, just as there are differences (and similarities) between any two species, any two cultures, or even any two individuals. However, since all traits cannot be taken into account simultaneously, it is inappropriate to accord superiority to a subset of traits that are preselected in a biased or ad-hoc fashion. Species can be compared on a suite of singled-out traits, as is done in multivariate university rankings, but the exercise is likely to be just as arbitrary.

We should use the traits we are so proud of - our vaunted intellect, communication skills, and morality - to create positive change. There is little doubt that now is the time when these skills are desperately needed. The world's ecosystems are in peril. Since our species is the major cause, we must provide solutions. Biodiversity is being lost at an accelerating rate, with current extinction rates approximately 1,000 times higher than background rates observed in the fossil record (Pimm et al., 2014). Extant vertebrate species have declined in abundance by approximately 25\% since 1970 (Dirzo et al., 2014). Between 2000 and 2012, 2.3 million $\mathrm{km}^{2}$ of forest were lost globally, and in the tropics, tropical forest loss has increased annually (Hansen et al., 2013).

To put this in perspective, the area of forest lost is approximately the size of Mexico. Global estimates of the extent of wildlife over-exploitation are very poor; however, in Africa, four million metric tons of bushmeat are extracted each year from the Congo basin alone (equivalent to approximately 4,500,000 cows, or 80 million small (5 kg) monkeys). (Not all bushmeat is primate; Fa and Brown, 2009.) Global temperature is predicted to increase by $1.5^{\circ} \mathrm{C}$ by the end of the $21^{\text {st }}$ century (IPCC, 2014) and researchers have projected that by $2100,75 \%$ of all tropical forests present in 2000 will experience temperatures that are higher than the temperatures presently supporting closed canopy forests (Wright et al., 2009; Peres et al., 2016).

These statistics illustrate that we continue to place human profit ahead of the rights of animals and the ecosystems that support them, not to mention the rights of future human generations. An example of the drive for profit is that the conversion of forest to oil palm plantations was responsible for 3 million hectares of deforestation from 20002011 (an area the size of the Philippines) (Vijay et al., 2016). This was a significant factor leading to the loss of 100,000 orangutans between 1999 and 2015 (Voigt et al., 2018). Ever more land is projected to be needed for agricultural activities because of human population growth and people electing to eat higher up on the food chain (Delgado, 2003). Yet this is also the time when people have options to use products not containing palm oil, to eat lower on the food chain, and to use products that do not support the deforestation of tropical forests. As the duration of inaction continues, the options available to society become progressively limited - climate change represents a clear example (IPCC, 2018).

Many human traits once thought unique to our species have proved to differ only in degree from those of many other species living on the planet. We cannot survive without many of those other species today; it is because of the existence of other species that we exist. We need to treat them with the respect they deserve and not judge their intelligence 
by how much they resemble us, nor evaluate them only on the basis of what they provide us. We need to acknowledge how much we resemble them and how much we have to learn from them. Doing so will allow us to make decisions - such as whether to use palm oil or how high on the food chain to eat - with a realistic understanding of the consequences of our actions, for them as well as for us.

Acknowledgements: The thoughts expressed in this article were developed from decades of sharing our days with primates in their natural environments on their terms. We would like to thank all the people we shared field experiences with and all the others, inside and outside the tropical forests, from whom we learned. We thank Selin Altuntur, Elizabeth Donison, Layan Elchaar, Augustine Fuentes, Simon L'Allier, Stevan Harnad, Greg Mikkelson, David Paterson, Rachel Sader, Rachel van Vliet, and Elsie Yan for helpful comments on the ideas presented.

\section{References}

Arluke, A. (2017) Just a dog: Understanding animal cruelty and ourselves. Temple University Press. Bauman, Z., Bigo, D., Esteves, P., Guild, E., Jabri, V., Lyon, D. \& Walker, R. B. (2014) After Snowden: Rethinking the impact of surveillance. International Political Sociology, 8, 121-144.

Bernardi, G. (2012) The use of tools by wrasses (Labridae). Coral Reefs, 31, 39.

Call, J. (2006) Descartes' two errors: Reason and reflection in the great apes. In Rational animals? (S. Hurley \& M. Nudds, Eds.). Oxford: Oxford University Press.

Carlyle, T. (1833) Sartor resartus (meaning 'the tailor re-tailored'). Fraser's Magazine.

Cartmill, M. (1990) Human uniqueness and theoretical content in paleoanthropology. International Journal of Primatology, 11, 173-192.

Darlington, J. P. (1985) The structure of mature mounds of the termite Macrotermes michaelseni in Kenya. International Journal of Tropical Insect Science, 6, 149-156.

Delgado, C. L. (2003) Rising consumption of meat and milk in developing countries has created a new food revolution. The Journal of Nutrition, 133, 3907S-3910S.

Dirzo, R., Young, H. S., Galetti, M., Ceballos, G., Isaac, N. J. B. \& Collen, B. (2014) Defaunation in the Anthropocene. Science, 345, 401-406.

Doucet, C. M., Adams, I. T. \& Fryxell, J. M. (1994) Beaver dam and cache composition: Are woody species used differently? Ecoscience, 1, 268-270.

Engel, C. (2002) Wild health. Boston: Houghton Mifflin.

Fa, J. E. \& Brown, D. (2009) Impacts of hunting on mammals in African tropical moist forests: A review and synthesis. Mammal Review, 39, 231-264.

Finn, J. K., Tregenza, T. \& Norman, M. D. (2009) Defensive tool use in a coconut-carrying octopus. Current Biology, 19, R1069-R1070.

Fuentes, A. (2017) Human niche, human behaviour, human nature. Interface Focus, 7, 20160136.

Fuentes, A. (2018) How humans and apes are different, and why it matters. Journal of Anthropological Research, 74, 151-167.

Fujii, J. A., Ralls, K. \& Tinker, M. T. (2014) Ecological drivers of variation in tool-use frequency across sea otter populations. Behavioral Ecology, 26, 519-526.

Goldschmidt, R. (1940) The material basis of evolution. New Haven: Yale University Press.

Goodall, J. (1964) Tool-using and aimed throwing in a community of free-living chimpanzees. Nature, 201, 1264.

Goodall, J. (1986) The chimpanzees of Gombe: Patterns of behaviour. London: Harvard University Press.

Hall, K. \& Schaller, G. B. (1964) Tool-using behavior of the California sea otter. Journal of Mammalogy, 45, 287-298. 
Hansell, M. (2000) Bird nests and construction behaviour. Cambridge University Press.

Hansen, M. C., Potapov, P. V., Moore, R., Hancher, M., Turubanova, S. A., Tyukavina, A., Thau, D., Stehman, S. V., Goetz, S. J., Loveland, T. R., Kommareddy, A., Egorov, A., Chini, L., Justice, C. 0. \& Townshend, J. R. G. (2013) High-resolution global maps of 21st-century forest cover change. Science, 342, 850-853.

Hart, B. L. \& Hart, L. A. (1994) Fly switching by Asian elephants: Tool use to control parasites. Animal Behaviour, 48, 35-45.

Haslam, M., Hernandez-Aguilar, R. A., Proffitt, T., Arroyo, A., Falótico, T., Fragaszy, D., Gumert, M., Harris, J. W., Huffman, M. A. \& Kalan, A. K. (2017) Primate archaeology evolves. Nature Ecology \& Evolution, 1, 1431.

Hepburn, H., Pirk, C. \& Duangphakdee, O. (2016) Honeybee nests. Springer.

Huffman, M. A. (1997) Current evidence for self-medication in primates: A multidisciplinary perspective. Yearbook of Physical Anthropology, 40, 171-200.

Huffman, M. A. (2007) Primate self-medication. In Primates in perspective (C. J. Campbell, A. Fuentes, K. C. MacKinnon, M. Panger \& S. K. Bearder, Eds.), pp. 677-690. Oxford: Oxford University Press.

Huffman, M. A., Gotoh, S., Turner, L. A., Hamai, M. \& Yoshida, K. (1997) Seasonal trends in intestinal nematode infection and medicinal plant use among chimpanzees in the Mahale Mountains, Tanzania. Primates, 38, 111-125.

Inoue, S. \& Matsuzawa, T. (2007) Working memory of numerals in chimpanzees. Current Biology, 17, R1004-R1005.

IPCC (2014) Climate change 2014: Synthesis report. Contribution of working groups I, II and III to the fifth assessment report of the Intergovernmental Panel on Climate Change (Core Writing Team, R. K. Pachauri and L. A. Meyer, Eds.). Geneva, Switzerland: IPPC.

IPCC (2018) Global warming of $1.5^{\circ} \mathrm{C}$. Geneva, Switzerland: IPCC.

Köhler, W. (1925) The mentality of apes (translated from the second revised edition by E. Winter). London: Kegan Paul, Trench, Trubner.

Korb, J. (2003) Thermoregulation and ventilation of termite mounds. Naturwissenschaften, 90, 212219.

Korb, J. (2010) Termite mound architecture, from function to construction. Biology of termites: A modern synthesis, pp. 349-373. Springer.

Kunst, J. R., Fischer, R., Sidanius, J. \& Thomsen, L. (2017) Preferences for group dominance track and mediate the effects of macro-level social inequality and violence across societies. Proceedings of the National Academy of Sciences, 201616572.

Kurki, V. A. \& Pietrzykowski, T. (2017) Legal personhood: Animals, artificial intelligence and the unborn. Springer.

Laidlaw, J. (1995) Riches and renunciation: Religion, economy, and society among the Jains. Oxford University Press.

Marks, J. (2015) Tales of the ex-apes: How we think about human evolution. University of California Press.

Marks, J. (2016) Tales of the ex-apes. General Anthropology, 23, 1-7.

Matsuzawa, T. (2017) The 40th anniversary of the Ai Project: The commemorative gift is a silk scarf painted by Ai the chimpanzee. Primates, 58, 261-265.

Mechoulan, S. (2017, winter) The European case against the face-veil. International Journal of Constitutional Law.

Nagano, A. \& Aoyama, K. (2017) Tool-use by rats (Rattus norvegicus): Tool-choice based on tool features. Animal Cognition, 20, 199-213.

Osler, W. (1891) Recent Advances in Medicine. Science 17: 170-171

Pepperberg, I. M. (2004) "Insightful” string-pulling in Grey parrots (Psittacus erithacus) is affected by vocal competence. Animal Cognition, 7, 263-266. 
Peres, C. A., Emilio, T., Schietti, J., Desmoulière, S. J. \& Levi, T. (2016) Dispersal limitation induces long-term biomass collapse in overhunted Amazonian forests. Proceedings of the National Academy of Sciences, 113, 892-897.

Pimm, S. L., Jenkins, C. N., Abell, R., Brooks, T. M., Gittleman, J. L., Joppa, L. N., Raven, P. H., Roberts, C. M. \& Sexton, J. O. (2014) The biodiversity of species and their rates of extinction, distribution, and protection. Science, 344, 1246752.

Popper, K. R. (1968) Conjectures and refutations: The growth of scientific knowledge. New York: Harper \& Row.

Shyam, G. (2015) The legal status of animals: The world rethinks its position. Alternative Law Journal, 40, 266-270.

Staub, E. (1989) The roots of evil: The origins of genocide and other group violence. Cambridge, UK: Cambridge University Press.

Taylor, N. \& Fraser, H. (2017) Slaughterhouses: The language of life, the discourse of death. In The palgrave international handbook of animal abuse studies, pp. 179-199. Springer.

Taylor, P. W. (1984) Are humans superior to plants and animals? Environmental Ethics, 6, 149-160.

Twining, H., Arluke, A. \& Patronek, G. (2000) Managing the stigma of outlaw breeds: A case study of pit bull owners. Society \& Animals, 8, 25-52.

van Casteren, A. (2017) Tool use: Crows craft the right tool for the job. Current Biology, 27, R1314R1316.

Van Schaik, C. P. (2016) The primate origins of human nature. New York: John Wiley \& Sons, Inc.

Vijay, V., Pimm, S. L., Jenkins, C. N. \& Smith, S. J. (2016) The impacts of oil palm on recent deforestation and biodiversity loss. PLOS ONE, 11, e0159668.

Voigt, M., Wich, S. A., Ancrenaz, M., Meijaard, E., Abram, N., Banes, G. L., Campbell-Smith, G., d'Arcy, L. J., Delgado, R. A. \& Erman, A. (2018) Global demand for natural resources eliminated more than 100,000 Bornean orangutans. Current Biology, 28, 761-769, e5.

Wise, S. (2014) Rattling the cage: Toward legal rights for animals. Da Capo Press.

Wright, S. J., Muller-Landau, H. C. \& Schipper, J. (2009) The future of tropical species on a warmer planet. Conservation Biology, 23, 1418-1426.

Call for Commentary: Animal Sentience publishes Open Peer Commentary on all accepted target articles. Target articles are peer-reviewed. Commentaries are editorially reviewed. There are submitted commentaries as well as invited commentaries. Commentaries appear as soon as they have been reviewed, revised and accepted. Target article authors may respond to their commentaries individually or in a joint response to multiple commentaries.

Instructions: animalstudiesrepository.org/animsent/guidelines.html 